\title{
Educational Perspectives: Integrating a Student Post-Stroke Clinic within a First-Year Occupational Therapy Kinesiology Course
}

\author{
Mark Blanchard \\ Louisiana State University Health Science Center, mblan5@Isuhsc.edu \\ Barbara M. Doucet \\ Louisiana State University Health Sciences Center New Orleans, bdouc3@Isuhsc.edu
}

Follow this and additional works at: https://nsuworks.nova.edu/ijahsp

Part of the Occupational Therapy Commons, and the Other Rehabilitation and Therapy Commons

\section{Recommended Citation}

Blanchard M, Doucet BM. Educational Perspectives: Integrating a Student Post-Stroke Clinic within a FirstYear Occupational Therapy Kinesiology Course. The Internet Journal of Allied Health Sciences and Practice. 2020 Jan 01;18(2), Article 1.

This Manuscript is brought to you for free and open access by the College of Health Care Sciences at NSUWorks. It has been accepted for inclusion in Internet Journal of Allied Health Sciences and Practice by an authorized editor of NSUWorks. For more information, please contact nsuworks@nova.edu. 


\title{
Educational Perspectives: Integrating a Student Post-Stroke Clinic within a First- Year Occupational Therapy Kinesiology Course
}

\begin{abstract}
ABSTRACT

Purpose: In many occupational therapy graduate programs, student experiences with actual patient evaluation and intervention typically occur following several semesters of didactic instruction. We explored the impact of an early immersive and reflective hands-on patient experience on student learning and clinical skill development. Method: Following participation in five task-specific occupational therapy clinical sessions that were embedded into an applied kinesiology course, students performed reflections on the experience. These reflections included thoughts on kinesiology course content and clinical skill development through patient sessions over the semester. Results: A qualitative thematic analysis of student reflections was conducted. Findings reflected themes of improvement in observation skills, intervention abilities and communication. Conclusion: Early reflective and immersive clinical experiences may be helpful in the reinforcement of course content and in the development of clinical skills of occupational therapy graduate students prior to full intervention content exposure.
\end{abstract}

\footnotetext{
Author Bio(s)

Mark Blanchard, OTD, LOTR, ATP, is an Assistant Professor of Occupational Therapy at Louisiana State University Health Sciences Center, New Orleans, LA

Barbara Doucet, PhD, LOTR, is an Associate Professor of Occupational Therapy at Louisiana State University Health Sciences Center, New Orleans, LA
}

\section{Acknowledgements}

The authors would like to thank the Christopher and Dana Reeve Foundation for their 2015 grant funded support of the LSUHSC Post-Stroke Clinic. 


\title{
TIAHSP
}

The Internet Journal of Allied Health Sciences and Practice

Dedicated to allied health professional practice and education

Vol. 18 No. 2 ISSN 1540-580X

\section{Educational Perspectives: Integrating a Student Post-Stroke Clinic within a First-Year Occupational Therapy Kinesiology Course}

\author{
Mark Blanchard \\ Barbara M. Doucet \\ Louisiana State University \\ United States
}

\begin{abstract}
Purpose: In many occupational therapy graduate programs, student experiences with actual patient evaluation and intervention typically occur following several semesters of didactic instruction. We explored the impact of an early immersive and reflective hands-on patient experience on student learning and clinical skill development. Method: Following participation in five task-specific occupational therapy clinical sessions that were embedded into an applied kinesiology course, students performed reflections on the experience. These reflections included thoughts on kinesiology course content and clinical skill development through patient sessions over the semester. Results: A qualitative thematic analysis of student reflections was conducted. Findings reflected themes of improvement in observation skills, intervention abilities and communication. Conclusion: Early reflective and immersive clinical experiences may be helpful in the reinforcement of course content and in the development of clinical skills of occupational therapy graduate students prior to full intervention content exposure.
\end{abstract}

Keywords: experiential learning, reflective learning, occupational therapy education, clinical reasoning 


\section{INTRODUCTION}

Although experiential hands-on patient care is a part of occupational therapy (OT) education, these activities are not typically employed in the early semesters of entry level graduate programs; however, positive outcomes in knowledge acquisition and critical thinking have been reported when novice learners in a healthcare curriculum are immersed into more advanced practice methods early in academic development. ${ }^{1}$

Immersion into direct patient care prior to completion of all instructive content has shown to have immense learning benefits beyond development of practical skills; namely, that learners are able to identify needed areas of emphasis for instruction within the program, and that they obtain a greater understanding of professional roles. ${ }^{2-3}$ Medical students who were exposed to patient care through a first-semester emergency medical technician (EMT) course embedded in a medical curriculum reported the significant benefit of being able to engage in actual patient care while being supervised by mentors. ${ }^{4}$

A four stage educational/experiential cycle has been described by Kolb which begins with active immersion or experimentation, then exposure to concrete experiences, followed by reflection, and then an emergence into abstract higher order conceptualization. ${ }^{5}$ This paper describes a creative instructional design that used these concepts to foster understanding of kinesiology content and development of clinical reasoning skills in novice occupational therapy students early in a Master of Occupational Therapy (MOT) curriculum. The design emphasizes the use of faculty guided patient care sessions through a free community post-stroke clinic embedded within the applied kinesiology course in the second semester of an MOT curriculum. This model was used to promote scaffolding of learning, defined as support from an expert that is gradually weaned or faded to the less experienced learner to transfer a skill or learning. ${ }^{6}$ The impact of this strategy was described by our students in both immediate group reflections (IGR) completed after each session, and delayed individual reflections (DIR) completed at the end of the semester. Through the use of structured kinesiology content modules and reflective learning, first year students were provided with rich learning activities and early exposure to patient care.

\section{Embedding Course Content into the Post-Stroke Clinic}

The Louisiana State University Health Sciences Center (LSUHSC) Post-Stroke Clinic is a free clinic established by the LSUHSC School of Occupational Therapy in 2015. The clinic provides free rehabilitation services to persons with stroke living in the New Orleans area who are underinsured or have exhausted insurance options. ${ }^{7}$ Prior to 2016, clients were seen for five to six treatment sessions during both the fall and spring semesters (third and fourth semesters of the program) which coincided with the MOT program assessment and intervention content. This study provides the findings we obtained when the clinic was offered to the students earlier in the curriculum (second semester, summer) and before full didactic instruction in intervention strategies. By doing so, students were immersed in hands-on patient care as part of the kinesiology course. The addition of the summer semester clinic provided students with the opportunity to be exposed to clinical skill learning earlier in the program while additionally providing year-round services to clients.

Although providing earlier client contact and student participation was a great opportunity for the program, the challenge was to integrate early curriculum content while at the same time providing meaningful occupational therapy services for the clinic patients. Thus, the integration of the applied kinesiology course into the post-stroke clinic involved combining short structured course learning modules and simple patient intervention activities. The modules contained specific learning objectives explained in class that the students were required to perform at the start of each treatment session. The remainder of the session consisted of facultydeveloped intervention tasks carried out by the students and supervised by faculty. During the student intervention, faculty were able to explain the rationale and outcomes being addressed through the selected tasks. Five applied kinesiology course modules were included to correspond to each of the five treatment sessions and course content objectives.

\section{Educational Module Description}

Two to three students were assigned to each client attending the clinic, and clinicians from the community were invited to assist faculty in supervising student/client groups in patient care and intervention. One faculty or community clinician (herein after referred to as clinical facilitators, [CF]) supervised and guided each student/client group. Typically, five to six CF were available for each clinic, therefore, CF sometimes supervised more than one student/client group. Clinical facilitators met with faculty prior to each clinic to insure consistency in the supervision and guidance needed for the students and to discuss specific goals and strategies for each client.

Five class modules with targeted questions and activities aligned with the five stroke clinics. A document including the specific module learning objectives and questions to be addressed during each session was provided to students and CF. Areas of content covered in each of the five modules, respectively, included 1) postural control, 2) functional range of motion assessment, 3) 
functional mobility, 4) upper extremity function, and 5) target heart rate. Kinesiology class content also included instruction in both normal and abnormal movement presentations and a review of stroke rehabilitation topics from a medical conditions course taken the prior (first) semester. Prior to the first clinic, students were introduced to the Canadian Occupational Performance Measure (COPM) and were trained to administer the instrument so occupational performance would be emphasized as the primary focus of the OT process. Students administered the COPM with the client during the first session of the stroke clinic.

During the initial portion of each client treatment session, students addressed the module learning objectives and the specific questions included in each module handout. CF provided assistance and direction with basic intervention tasks for the remainder of the session and addressed occupational performance goals as indicated from the COPM results. CF discussed clinical decisions, alternate approaches, and basic intervention strategies with student groups during briefings held before and after treatment sessions. Students also performed IGR with CF at the end of each treatment session to address the kinesiology content area.

Following completion of both the summer post-stroke clinic and kinesiology course, students performed DIR that addressed the content areas from each of the five kinesiology modules (Figure 1). The guided open-ended reflections used their own completed handouts from each module to facilitate discussions regarding observations and clinical experiences. Data from the IGR completed during the semester and the DIR after the semester were transcribed and a thematic analysis was conducted to evaluate predominating themes and assess the efficacy of the clinical experience.

Reflection on Stroke Clinic \#1: Observation of Posture and Anatomy:

A) Describe what you learned from this observation.

B) If you had to do this assignment today, would your observation be the same or different? Explain.

C) Describe the differences noted in normal postures and those in your client with stroke.

D) Describe your level of comfort with physically assisting and interacting with the client at the first clinic. Has the level of comfort with your client changed? Describe.

E) Describe your participation/use of the COPM interview assessment during your first clinic. If you had to use the COPM today, would you administer it the same or differently? Explain.

Figure 1. Delayed Individual Reflection Items (DIR) for Stroke Clinic \#1

\section{Reflective Learning}

The use of both short-term feedback through IGR and long-term feedback through DIR facilitated scaffolding of student learning during the kinesiology and post-stroke clinic experience. Researchers have described the benefit of using immediate reflections to facilitate day to day improvements from real events while also using delayed reflection for long-term processes to foster clinical competency development. 6 Both immediate reflections of clinical decisions and delayed reflections on the overall clinical experiences were used to encourage comprehensive student learning during the clinic. Eva and Regehr identified this combination of immediate and delayed reflections as a key component to promote professional development. ${ }^{8}$

The structure of the IGR included group and faculty dialogue following each treatment session. This type of interchange has been advocated as an effective approach to foster clinical reasoning. ${ }^{9} \mathrm{~A}$ debriefing format was incorporated to facilitate long-term recall of the clinical actions where students could reflect upon and process the benefit of the immersive experience. This debriefing concept was used to promote long term learning and is an important component as the experiential process took place over an entire summer semester kinesiology course. ${ }^{10}$ This format built on the knowledge from each of the five sessions and promoted meaningful and critical reflection. ${ }^{11}$

Reflective learning has also been identified to promote both clinical reasoning and lifelong learning in the field of occupational therapy. The use of critical reflection was identified by Royeen as an educational tool to foster clinical reasoning and skills development; she noted that this type of learning is important at all levels of occupational therapy education from the early stages of entry level education to clinical competency and professional development for experienced clinicians. ${ }^{12}$ Occupational therapy practitioners' have also been called upon to use reflective practice as a means for professional development. ${ }^{13}$ Thus, the use of 
both immediate and delayed reflections in the kinesiology course were important to the student learning process and allowed faculty investigators to better assess student learning. ${ }^{14}$

\section{ASSESSMENT}

The use of open ended and guided questions was necessary to provide structure and emphasis on the kinesiology content from the stroke clinic experience. This type of structured reflection has been shown to be important in shaping student perspectives and clinical practice ${ }^{14}$. While the MOT students reflected on each content area from the structured kinesiology content, they also provided feedback on the overall stroke clinic learning experience (Figure 2). This overall reflection was an important component of the hands-on learning experience and addressed an essential need to better understand how the clinical reasoning process occurs. ${ }^{15}$

Reflections on Stroke Clinic:

A. Reflect on the overall experience of the stroke clinic and the integration of the clinic into your Kinesiology class.

B. Describe what you learned from being exposed to: evaluating clients, treating patients, note writing, goal setting, charges, etc. prior to formal training in these areas.

Figure 2. End of Semester Delayed Individual Reflection (DIR) Prompts

\section{Thematic Analysis}

Institutional Review Board approval was obtained for this project as educational research to examine effectiveness of standard instructional techniques (\#9177). As such, submissions of reflections and question responses were voluntary and students could elect not to participate; however, the final data set included responses from the entire class of 34 students for IGR and 34 responses for DIR. Student reflection narrative responses from IGR and DIR were extracted, input onto spreadsheets, and organized into themes and categories. Investigators chose to analyze the anonymous DIR in order to emphasize the long-term learning experience of the participants. The data analyzed included the responses from the guided reflections and open-ended questions provided during the five learning modules.

A six-phase thematic analysis was performed using the step by step process as outlined by Braun and Clark for analyzing qualitative data ${ }^{16}$. Two investigators (one not associated with the project) skilled in qualitative methods performed the analysis. The faculty used a process of transcription, code generation, theme search, naming, review, and report. Categories were then extracted using techniques recommended by Saldana and themes then emerged from the student reflections. ${ }^{17}$

The data from each of the DIR were included in a six-part reflection, five of which addressed each stroke clinic and corresponding themed kinesiology content area. The final part of the reflection addressed the overall stroke clinic experience and the clinical actions performed by the student. The compiled data from the five individual reflections were assessed separately from the final reflection to evaluate the learning experience of each stroke clinic and the overall student experience.

\section{Reflection Theme Categories}

Predominating themes from the reflections were divided into four categories. The categories that emerged included observation skills, interventions skills, communication skills, and professional behaviors (Figure 3). The student reflections on improvements in both observation skills and client interactions were consistent throughout all five stroke clinic modules. The most consistent theme focused on the student's improved ability to recognize, analyze and observe the client from both a biomechanical and behavioral perspective. 
Kinesiology Reflection Theme Categories

1. Observation Skills: description of specific concrete observations of client postures, movement, tonal changes, functional movements

2. Intervention Skills: descriptions of biomechanical and occupational based treatment approaches as well as descriptions of rationale

3. Communication Skills: details of client interactions and understanding of patient needs

4. Professional Behaviors: description of actions of personal/social responsibility, supervision and commitment to learning.

Figure 3. Categorization of Themes

Although improved observation skills were the most prevalent theme, improvement in student level of comfort with both client handling and interaction were frequently reported. Descriptions of specific client interactions and experiences were reported along with rationale for the clinical decisions made. Figure 4 provides a specific breakdown of each clinic module and details regarding self-reflection improvements in specific observation skills, client interactions and intervention development.

\begin{tabular}{|c|c|}
\hline Stroke Clinic Module Area & $\begin{array}{c}\text { Frequently Reported Themes and Sub-Themes } \\
\text { From Student Delayed Individual Course } \\
\text { Reflections (DIR) }\end{array}$ \\
\hline $\begin{array}{l}\text { Stroke Clinic \#1: } \\
\text { Observation of Posture and Anatomy }\end{array}$ & $\begin{array}{l}\text { Improved Observation Skills } \\
\text { Noticing postural alignment/deviations } \\
\text { Identifying asymmetries in posture } \\
\text { Identification of patterns of spasticity } \\
\text { Depth of observation } \\
\text { Use of terminology } \\
\text { Client Interaction Skills } \\
\text { More comfortable (initial anxiety, nervousness reduced) } \\
\text { Heightened patient awareness/empathy } \\
\text { Confidence in communication with client } \\
\text { Intervention Skills } \\
\text { Patient handling/physically assisting client }\end{array}$ \\
\hline $\begin{array}{l}\text { Stroke Clinic \#2: } \\
\text { Assessment of Functional Mobility }\end{array}$ & $\begin{array}{l}\text { Improved Observation Skills } \\
\text { Depth of gait knowledge (More specific) } \\
\text { Awareness of arm swing } \\
\text { Notice of compensatory patterns } \\
\text { Weight shift/symmetry of posture } \\
\text { Cognition and function during functional mobility }\end{array}$ \\
\hline $\begin{array}{l}\text { Stroke Clinic \#3: } \\
\text { Functional Range of Motion }\end{array}$ & $\begin{array}{l}\text { Improved Observation Skills } \\
\text { Awareness of functional limitations } \\
\text { Affected vs non-affected side } \\
\text { Muscle tightness/ spasticity } \\
\text { Proximal to distal } \\
\text { Client Interaction Skills } \\
\text { Awareness of pain } \\
\text { Intervention } \\
\text { Patient handling/physically assisting client }\end{array}$ \\
\hline $\begin{array}{l}\text { Stroke Clinic \#4: } \\
\text { Readiness for Function and Upper Trunk } \\
\text { Movement }\end{array}$ & $\begin{array}{l}\text { Improved Observation Skills } \\
\text { Analysis from proximal to distal } \\
\text { Awareness of pelvic alignment } \\
\text { Awareness of scapular alignment } \\
\text { Postural asymmetries/spasticity } \\
\text { Scapulohumeral rhythm } \\
\text { Intervention } \\
\text { Assisting with mobilization }\end{array}$ \\
\hline
\end{tabular}

@ The Internet Journal of Allied Health Sciences and Practice, 2020 


\begin{tabular}{|l|l|}
\hline Stroke Clinic \#5: & Improved Observation Skills \\
Calculating Target Heart Rate and & Exertion of clients with stroke vs non-stroke \\
Perceived Rate of Exertion (PRE) & Accuracy of PRE with clients with stroke \\
& Client Interaction Skills \\
\hline Challenges of limited awareness/cognitive ability \\
\hline
\end{tabular}

Figure 4. Frequently Reported Themes and Sub-themes From Clinic Reflections.

\section{Overall Reflection}

The last portion of the DIR focused on the students overall experience in the stroke clinic. The two part reflection first emphasized an open ended question regarding the integration of the kinesiology content into the stroke clinic. Next, the reflection asked each student to identify the specific clinical reasoning skills they perceived were developed from the experiential process. The final overall reflection themes stressed the student development that took place as a result of the hands-on and real-life patient care experiences. Students reported an increased comfort level with handling and interacting with clients as well as an improved ability to make clinical decisions. Also, they reported more proficiency in the ability to identify, differentiate, and understand lecture content as a result of the experience, and described an improved ability to formulate realistic client centered goals. Figure 5 provides specific quotes from students that are descriptive of the overall stroke clinic and applied kinesiology class experience.

\begin{tabular}{|c|}
\hline "For me this is how I learn best, by being thrown into a situation" \\
\hline "I learned knowledge that I don't think I could have properly understood from a lecture" \\
\hline "I felt like I was involved and making a difference" \\
\hline "I now know to always start off observations and work from proximal to distal" \\
\hline "I feel way more comfortable actually putting my hands on a patient" \\
\hline "This experience has taught me to be more independent in what I do and more confident" \\
\hline "I have learned to be more aware and more observant" \\
\hline "It was overwhelming at first but it really helped me to gain understanding for the concepts. \\
I felt more and more comfortable each week" \\
\hline "Overall, I felt this experience taught me what it means to be an OT" \\
\hline "I felt unprepared at times but later appreciated the tough love approach because it really pushed me to think on my toes" \\
\hline "It gave me the chance to apply concepts I've learned to real patients \\
and opened my eyes to what I may see as a practitioner" \\
"In the very beginning of stroke clinic, I think I had tunnel vision \\
when it came to observing posture and abnormal movements \\
\hline "Applying what we learned from lecture to real life has accelerated my understanding greatly"
\end{tabular}

Figure 5: Quotes from Student Reflections

\section{DISCUSSION}

This study describes reported perceptions of student learning that occurred by embedding a free teaching stroke clinic into kinesiology content early in the curriculum of an MOT program. The students were provided specific instructions that allowed for simple interpretation of normal and abnormal movement patterns. This allowed the novice students to build confidence in observation and analysis skills while still being guided by faculty to make more advanced clinical decisions. Reflections indicated significant depth and understanding of kinesiology principles as well as confidence in making these intervention decisions.

Proficiency in the understanding of these principles, however, does not suggest improvements in clinical reasoning. Mattingly suggests that clinical reasoning involves both clinical experiences and reflections on the experiences. ${ }^{18}$ Thus, student reflections did not focus solely on objective knowledge, but also emphasized an empathy and understanding of client needs. A combination of both of these learning strategies has been shown to be critical in gaining clinical reasoning skills. ${ }^{19}$ Although the predominating 
themes from the reflections emphasized heightened observation skills, a significant amount of feedback focused on professionalism and client communication indicative of higher-level clinical decision making.

The end of course reflections provided rich details of an effective method of developing clinical reasoning skills. These skills were especially evident as the new learners described improved client observations, detailed learning of occupation-based interventions, enhanced client communication, and an increased level of comfort in making clinical decisions.

\section{STUDY LIMITATIONS}

Despite informative outcomes, we noted limitations with the study. Differences in the detail and content of the reflections were noted from the DIR when compared to the IGR. This may have impacted the results of the study and not fully captured the clinical learning at the time it was experienced. Also, the use of other qualitative designs may have better captured the students understanding and competency. Stickler et al used focus groups as a means to analyze student participation in a clinical setting. ${ }^{20}$ A structured clinical module reflective design with both peer and student input has also been used to help pharmacy students make more informed clinical decisions. ${ }^{21}$

Mixed methods may have been more useful in determining the overall effectiveness of this clinical learning experience. KnechtSabres used a comprehensive approach to assess student learning that included a pretest and posttest to determine competency in technical skills and written feedback to determine improvement in clinical reasoning. ${ }^{22}$ The same skills competency was used in another study by the same authors and provided a numeric score of self-perceived competency for occupational therapy students participating in a clinical learning experience. ${ }^{23}$ This type of quantitative instrument may have been useful in providing more clarity to the competency level achieved by our students participating in the structured kinesiology modules.

\section{CONCLUSIONS}

Educators are challenged by integrating the new learner into a clinical setting without providing concrete goals and objectives. Often the student does not know what to observe or how to proceed when attempting to make clinical decisions. This creative instructional model integrated structured kinesiology coursework that prepared the student to perform simple procedures along with faculty guidance to facilitate clinical reasoning development. Thus, the student was immersed in patient care at an early point in the academic trajectory that allowed development of important foundational skills.

The effectiveness of this type of model is contingent on multiple factors. First, the current course content must be straightforward and easy to apply to a clinical environment. This was provided to the occupational therapy students through treatment modules that ranged from performing simple observations and interviews to functional range of motion assessments. Kinesiology course content was reinforced through concrete structured modules and accounted for a small portion of the overall stroke client treatment. These clinical experiences were structured to allow the novice student to successfully provide simple occupational therapy procedures and observations for a portion of the client treatment while promoting self-confidence and professionalism.

Next, the model emphasized guided occupation-based interventions in which the CF outwardly describes his or her rationale for the clinical decisions. The treatment sessions included debriefing and group discussions before and after sessions and feedback was provided to students on overall performance.

\section{IMPLICATIONS FOR OCCUPATIONAL THERAPY EDUCATION}

This project emphasizes the benefit of reflective learning. Occupational therapy students should reflect on both the academic and clinical experiences in which they are involved and perform self-evaluations of performance. Immediate reflections allowed for reinforcement of the procedures and structured tasks; more in-depth delayed reflections can be used to assess overall course learning and clinical reasoning. 


\section{References}

1. Costley A. Exploring skills-based competencies through geriatric care management modules. Geront Geri Educ. 2016; 37(4):329-41.

2. Sanders KA, McLaughlin JE, Waldron KM, Willoughby I, Pinelli NR. Educational outcomes associated with early immersion of second-year student pharmacists into direct patient care roles in health-system practice. Curr Pharm Teach Learn. 2018; 10(2): 211-19. S1877-1297(16)30359-8.

3. House JB, Cedarbaum J, Haque F., Wheaton M, Vredeveld J, Purkiss J, Daniel M. Medical student perceptions of an initial collaborative immersion experience. J Interprof Care. 2016; 32(2): 245-49. 10.1080/13561820.2017.137769.

4. Brenner J, Bird J, Ginzburg SB, Kwiatkowski T, Papsodero V, Rennie W, Willey JM. Trusting early learners with critical professional activities through emergency medical technician certification. Med Teach. 2018; 40(6):1-8.

10.1080/0142159X.2018.1444745

5. Kolb D. Experiential learning: experience as the source of learning and development. Englewood Cliffs, NJ: Prentice Hall; 1984.

6. Embo M, Driessen E, Valcke M, Van Der Vleuten C. Scaffolding reflective learning in clinical practice: A comparison of two types of reflective activities. Med Teacher. 2014; 36(7): 602-7. 10.3109/0142159X.2014.899686

7. LSU Health Foundation. Annual Report 2015-2016. Retrieved from http://annualreport.lsuhealthfoundation.org/blog/wpcontent/uploads/2016/12/LSU_Health_2015-2016_AnnualReport_web.pdf

8. Eva KW, Regehr G. Exploring the divergence between self-assessment and self-monitoring. Adv Health Sci Educ. 2011; 16(3):311-29. http://doi.org/10.1007/s10459-010-9263-2

9. McLeod GA, Barr J, Welch, A. Best practice for teaching and learning strategies to facilitate student reflection in preregistration health professional education: an integrative review. Creative Educ. 2015; 6:440-54.

10. Haque F, Daniel M, Clay M, Vredeveld J, Santen S, House JB. (2017). The interprofessional clinical experience: introduction to interprofessional education through early immersion in health care teams. J Teach Learn Resourc. 2017;13:10564. 10.15766/mep_2374-8265.10564

11. Cant RP, Cooper SJ. The benefits of debriefing as formative feedback in nurse education. Aust $J$ Adv Nurs. 2011; 29(1):37-47.

12. Royeen C. A problem-based learning curriculum for occupational therapy education. Am J Occup Ther.1995; 49(4):338-46. 10.5014/ajot.49.4.338

13. Kinsella E. Reflections on reflective practice. Can J Occup Ther. 2001; 68(3):195-8.

14. Asselin M. Using reflection strategies to link course knowledge to clinical practice: the RN-to-BSN student experience. J Nurs Educ. 2011; 50(3):125-33.

15. Coker P. (2010) Effects of an experiential learning program on the clinical reasoning and critical thinking skills of occupational therapy students. J Allied Health. 2011; 39(4):280-6.

16. Braun V, Clarke, V. Using thematic analysis in psychology. Qual Res Psych. 2006; 3(2):77-101. http://eprints.uwe.ac.uk/11735

17. Saldana J. Coding manual for qualitative researchers. Los Angeles, CA: Sage Publications; 2008.

18. Mattingly C. What is clinical reasoning? Amer J Occup Ther. 1991; 45:979-86.

19. Neistadt M. Classroom as clinic: a model for teaching clinical reasoning in occupational therapy education. Amer $J$ Occup Ther. 1987; 41(10):631-37.

20. Stickler L, Grapczynski C, Ritch J. Student perceptions of outcomes from participation in physical therapy pro bono clinics: a qualitative study. J Allied Health. 2013; 42(1):46-55.

21. Tsingos-Lucas $C$, Bosnic-Anticevich $S$, Schneider $C R$, Smith $L$. The effect of reflective activities on reflective thinking ability in an undergraduate pharmacy curriculum. Amer J Pharmaceut Educ. 2016; 80(4):65. 10.5688/ajpe80465

22. Knecht-Sabres LJ. Experiential learning in occupational therapy: can it enhance readiness for clinical practice? J Experient Educ. 2013; 36(1):22-36.

23. Knecht-Sabres LJ. The use of experiential learning in an occupational therapy program: can it foster skills for clinical practice? Occup Ther Health Care. 2010; 24(4):320-34. 10.3109/07380577.2010.514382 